\title{
Body mass index and the risk of dementia - what do we know and what should we do?
}

\author{
${ }^{1} \mathrm{JK}$ Harrison, ${ }^{2} \mathrm{SD}$ Shenkin \\ ${ }^{1}$ Academic Clinical Fellow, Geriatric Medicine, University of Leicester \& Department of Cardiovascular Sciences, Leicester Royal Infirmary, \\ Leicester, UK; ${ }^{2}$ Honorary Consultant, NHS Lothian, Edinburgh, UK \& Senior Clinical Lecturer, Centre for Cognitive Ageing and Cognitive \\ Epidemiology, Department of Geriatric Medicine, University of Edinburgh, Edinburgh, UK
}

TITLE BMI and risk of dementia in two million people over two decades: a retrospective cohort study

AUTHORS Qizilbash N, Gregson J, Johnston ME et al.

JOURNAL Lancet Diabetes Endocrinol 20I5; 3: 43I-6. http://dx.doi.org/I0.1016/ S22। 3-8587( I 5)00033-9

DECLARATION OF INTERESTS No conflicts of interests declared

\author{
Correspondence to SD Shenkin \\ Geriatric Medicine, Room SI642 \\ Department of Clinical and \\ Surgical Sciences \\ The University of Edinburgh \\ Royal Infirmary of Edinburgh \\ 5I Little France Crescent \\ Edinburgh EHI6 4SB \\ UK
}

e-mail susan.shenkin@ed.ac.uk

\section{SUMMARY}

'Being overweight can cut risk of dementia'. The news that a health status usually associated with poor outcomes and stigma may actually be protective for one of the most feared diseases of our time was enthusiastically greeted by the media and many individuals. The reports focused on this aspect - that risk of dementia fell with increasing body mass index (BMI) - although the authors of the study focused on the findings that being underweight in middle and old age carries an increased risk of dementia. Previous findings in this area have been contradictory, and appropriate interpretation is vital in view of the public health implications if the message that obesity is protective against dementia were to be accepted.

The study was a large retrospective cohort study using routinely collected UK primary care data, from the Clinical Practice Research Datalink (CPRD) database. Individuals' records were accessed if they were aged $>=40$ years between 1992 and 2007. Data from I,958,19I participants were used, comprising just $32 \%$ of those in the CPRD database of the appropriate age group. The population characteristics are not presented in the paper. BMI and incident dementia data were collected between January 1992 and December 2013. First recorded $\mathrm{BMI}$ was used and no subsequent changes in BMI were included. Median follow-up time was 9.1 years, although the conclusions are presented as data over two decades.

During the period of follow-up 45,507 people ( $2 \%$ of total sample) developed incident dementia. Coding of dementia was based on the use of the terms dementia, Alzheimer, Lewy body disease, Pick's disease, being used in the individual record or on death certificate.
The underweight group $\left(\mathrm{BMI}<20 \mathrm{~kg} / \mathrm{m}^{2}\right) \mathrm{n}=101,754,5 \%$ of the total sample, had a $34 \%$ excess risk of dementia compared to those of a healthy weight. Incidence of dementia fell as BMI category increased adjustment for potential confounders - smoking status, alcohol use, statin use, antihypertensive use, diabetes and previous myocardial infarction - did not affect the association.

\section{CLINICAL OPINION}

The paper is interesting in its use of a large sample, and routinely collected data, to investigate an important health topic, but some methodological issues, in particular the incomplete data availability, merit caution in the interpretation of the findings.

As an observational study, the results can only describe an association; causation cannot be attributed. The authors acknowledge that the association between weight and risk is complex. Flegal et al.,' in a systematic review and meta-analysis, also identified that being overweight is associated with lower mortality than being of normal weight; however the relationship was not seen in those who were obese. On the other hand, other studies report that overweight is not associated with lower dementia risk. Kivipelto et al. ${ }^{2}$ focused on the impact of vascular risk factors in middle age and were able to adjust for sociodemographic variables not included in the current study. They found increased odds (odds ratio 2.4) of dementia if obesity was present in midlife.Whitmer et al. ${ }^{3}$ adjusted for additional comorbid conditions including hyperlipidaemia and diabetes and found a hazard ratio of 1.74 from mid-life obesity on later life dementia. Whitmer et al. were also able to use body composition measurements in addition to BMI. ${ }^{3}$ Most recently, Albanese et al. ${ }^{4}$ evaluated brain imaging over a mean of 26.2 years and found no 
evidence to support the view that raised $\mathrm{BMI}$ in midlife reduced risk of dementia.

The rate of incident dementia in the sample is low, ${ }^{5}$ due in part to the inclusion of people aged $>40$ when the peak dementia incidence occurs in the oldest old, ${ }^{6}$ and in part to the comparatively short follow-up. The use of routine data to explore these issues, rather than relying on people recruited to studies, is to be commended, but the recording of dementia in the clinical record is far from complete. Furthermore, the lack of inclusion of coding for vascular dementia may miss many cases, and is concerning given the associations between vascular risk, obesity and dementia. Identification of dementia by means of death certification is thought to identify only $\sim 70 \%$ of cases. ${ }^{7}$ Although the authors state that this is unlikely to change any associations, this is unproven, and for future research there is an urgent need to improve the recording of dementia in electronic health records.

Doctors caring for older people are more familiar with frailty than obesity, and with the challenges of using BMI due to changes in body composition and loss of height. ${ }^{8}$ Also, the other health consequences of obesity mean that many individuals do not survive to older age to develop dementia - the problem of competing risks. The authors address this by performing sensitivity analysis, but it is still possible that survival bias contributed to the findings. Although the data are statistically corrected for a range of confounders, a major issue is the lack of information on clinically significant comorbidities causing both lower weight and a higher risk of dementia.

This study is not the final word on this complex issue, but shows the power (and limitations) of the use of electronic health records to answer important public health questions. There is a need for better integration of research findings using both observational and interventional methods. The relationship between body composition and dementia is complex, and genetics, diet, exercise, frailty, illness and vascular risk factors will all play a role. This study has raised more questions than it has answered at a public health level, but has raised awareness of the importance of vascular risk factors for cognitive as well as physical health. At present clinicians should continue to encourage patients to maintain a healthy weight (through diet and exercise) for their overall health.

\section{REFERENCES}

I Flegal KM, Kit BK, Orpana $\mathrm{H}$ et al. Association of all-cause mortality with overweight and obesity using standard body mass index categories: a systematic review and meta-analysis. JAMA 20। 3; 309: 7I-82. http://dx.doi.org/I0.100 I/jama.20I2.II3905

2 Kivipelto M, Ngandu T, Fratiglioni L et al. Obesity and vascular risk factors at midlife and the risk of dementia and Alzheimer disease. Arch Neurol 2005; 62: I556-60.

3 Whitmer RA, Gunderson EP, Barrett-Connor E et al. Obesity in middle age and future risk of dementia: a 27 year longitudinal population based study. BM/ 2005; 330: I 360.

4 Albanese E, Davis B, Jonsson P et al. Overweight and Obesity in Midlife and Brain Structure and Dementia 26 Years Later. The AGES-Reykjavik Study. Am J Epidemiol 2015; 18I: 672-9. http:// dx.doi.org/I0.1093/aje/kwu33 I
5 Matthews F, Brayne C. The incidence of dementia in England and Wales: findings from the five identical sites of the MRC CFA Study. PLoS Med 2005; 2: el 93.

$6 \mathrm{Gao}$ S, Hendrie HC, Hall KS et al. The relationships between age, sex, and the incidence of dementia and Alzheimer disease. Arch Gen Psychiatry 1998; 55: 809-15.

7 Russ T, Batty G, Starr J. Cognitive and behavioural predictors of survival in Alzheimer disease: results from a sample of treated patients in a tertiary-referral memory clinic. Int J Geriatr Psychiatry 20I2; 27: 844-53. http://dx.doi.org//0.1002/gps.2795

8 Han T, Tajar A, Lean M. Obesity and weight management in the elderly. Br Med Bull 201।; 97: 169-96. http://dx.doi.org//0.1093/ bmb/ldr002 